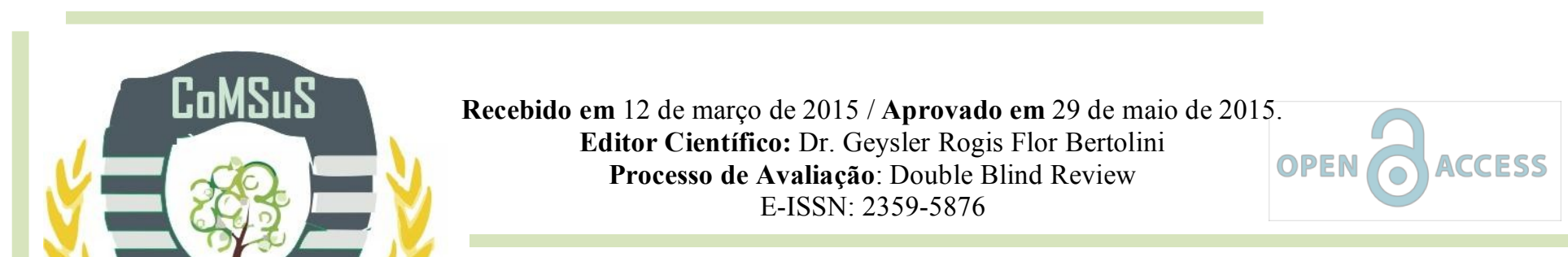

https://doi.org/10.5935/2359-5876.20150005

\title{
IABILIDADE ECONÔMICA E SUSTENTABILIDADE, RELAÇÕES ANTAGÔNICAS OU COMPLEMENTARES?
}

\author{
Antonio Oliveira de Carvalho \\ Doutorando em Administração pelo Programa de Pós-Graduação em Administração - PPGA \\ Universidade Nove de Julho - UNINOVE, Brasil \\ Professor do Centro Universitário Jorge Amado - UNIJORGE, Brasil \\ professorcarvalho@rocketmail.com \\ Claudia Brito Silva Cirani \\ Doutora em Economia pela Escola Superior de Agricultura Luiz de Queiroz da \\ Universidade de São Paulo ESALQ / USP, Brasil \\ Professora do Programa de Pós-Graduação em Administração - PPGA da \\ Universidade Nove de Julho - UNINOVE, Brasil \\ claudiacirani@uninove.br
}

Ivano Ribeiro Doutorando em Administração pelo Programa de Pós-Graduação em Administração - PPGA Universidade Nove de Julho - UNINOVE, Brasil ivano.adm@gmail.com

Renato Fabiano Cintra Doutorando em Administração pelo Programa de Pós-Graduação em Administração - PPGA Universidade Nove de Julho - UNINOVE renatocintra@hotmail.com

\begin{abstract}
RESUMO
O objetivo deste artigo é discutir a viabilidade econômica das empresas e a sustentabilidade como aspectos da gestão empresarial contemporânea. A viabilidade econômica foi polarizada durante séculos como o argumento central do desenvolvimento econômico, porém, conduziu o mundo a situação de crises múltiplas e a um grande desafio para as empresas, o de alcançar um modelo de negócio sustentável e menos predatório, sem gerar riscos para o negócio, sem desviá-los do core business e sem elevar os custos e perder lucratividade. Para discutir essa relação, realizamos um estudo partindo de uma análise bibliográfica focada em duas áreas: a viabilidade econômica baseada na moderna teoria de finanças e a responsabilidade social como aspecto determinante do sucesso dos negócios. Em seguida realizamos a análise de desempenho financeiro de empresas integrantes do Ibovespa (índice principal da bolsa de valores de São Paulo) comparando-as com empresas integrantes do ISE Índice de Sustentabilidade Empresarial da mesma bolsa estabelecendo como condição que cada empresa analisada não fosse integrante dos dois índices simultaneamente. Os resultados apontam a existência de diferenças positivas de desempenho das empresas do ISE em relação às empresas do Ibovespa, confirmando a proposição levantada neste trabalho de que as empresas podem ser economicamente viáveis e sustentáveis simultaneamente e que os dois aspectos não são mutuamente excludentes. Este trabalho pode contribuir para a academia e para a gestão empresarial na medida em que provoca uma reflexão sobre a associação da sustentabilidade e da viabilidade econômica de negócios de forma complementar.
\end{abstract}

Palavras-chave: Finanças corporativas, Sustentabilidade, Viabilidade econômica, Desenvolvimento econômico.

Revista Competitividade e Sustentabilidade - ComSus, Paraná, V. 2, N. 1, P. 63-75, Jan /Jun. 2015. 


\begin{abstract}
The purpose of this article is to discuss the economic viability of businesses and sustainability as aspects of contemporary business management. The economic viability was polarized for centuries as the central argument of economic development, but led the world the situation of multiple crises and a major challenge for companies to achieve a sustainable and less predatory business without generating risks for the business, without diverting them from the core business without increasing costs and lost profits. To discuss this relationship, we conducted a study starting from a literature review focused on two areas: the economic viability based on modern finance theory and social responsibility as a key aspect of business success. Then we analyze the financial performance of the companies comprising the Bovespa (the main index of the São Paulo Stock Exchange) comparing them with member companies of the ISE - Corporate Sustainability Index in the same Stock Exchange as establishing condition that each company analyzed were not part the two ratios simultaneously. The results show the existence of positive differences in performance of the ISE companies compared to companies in the Bovespa index, confirming the proposition raised in this paper that companies can be both economically viable and sustainable and that the two aspects are not mutually exclusive. This work can contribute to academia and business management in that it causes a reflection on the association of sustainability and economic viability of business in a complementary way.
\end{abstract}

Keywords: Corporate financial, Sustainability, Economic viability, Economic development. 


\section{INTRODUÇÃO}

Dentre as discussões contemporâneas sobre a gestão de negócios, o desafio da sustentabilidade ganha força. Ou seja, a criação de novos negócios ou a conversão dos já existentes para um modelo pautado nos quatro pilares da sustentabilidade: economicamente viável, ecologicamente correto, socialmente justo e culturalmente aceito, tem ganhado força e está presente em todos os âmbitos da sociedade global. O desafio de gerar negócios capazes de atender as necessidades atuais do mercado e da sociedade, sem gerar efeitos adversos e comprometer as gerações futuras, tornou-se imperativo para as empresas. Desenvolver negócios sustentáveis, no entanto, não é algo simples, demanda revisão de processos, de produtos e de estratégias e essas mudanças geram insegurança para os gestores, pois, temem perder lucratividade, aumentar custos ou desviar-se do seu core business.

\begin{abstract}
A sociedade está emergindo [...] três exigências econômicas estreitamente relacionadas [...] 1) a necessidade de suprir os bens de consumo e serviços requeridos; 2) a necessidade de assegurar que essa produção e seu consumo não exerça efeito adverso sobre o atual bem-estar do público em geral; e 3) a necessidade de assegurar que não afetem adversamente as vidas e o bem-estar das gerações futuras (KARKOTLI e ARAGÃO, 2010 p. 34).
\end{abstract}

No cenário atual, de crises, as externalidades geradas pelas empresas, positivas ou negativas, estão visíveis e observadas todo o tempo pelos seus diversos públicos de interesse (MACHADO et al., 2012). Esta observação impõe o fortalecimento da ótica social e das práticas de Responsabilidade Social Corporativa (RSC) que à primeira vista podem se opor ao desempenho financeiro (REZENDE; NUNES; PORTELA, 2008). Sendo o objetivo da empresa voltado para a satisfação do retorno exigido pelos seus proprietários, conforme destaca Assaf Neto (2003), autores como Flammer (2013), sublinham o questionamento "se a responsabilidade social pode contribuir com o desempenho financeiro e se existem evidências de uma relação positiva entre os dois".

O papel das finanças corporativas consiste em criar estrutura capaz de organizar operações de negócios e o pensamento dos diretores e administradores para maximizar o valor da riqueza dos proprietários da empresa (SALAZAR, 2010 p. 181). No entanto, argumentos diversos têm sido elaborados sobre a relação entre a responsabilidade social e o desempenho financeiro, uma ótica que provoca as empresas a enfrentarem um trade-off (McGUIRE; SUNDGREN; SCHNEEWEIS, 1988). Há um crescimento do campo da responsabilidade social, porém, autores como Tsoutsoura (2004) destacam o contínuo debate sobre a legitimidade e o valor das respostas sociais das empresas e o seu papel na sociedade, sobre se a maximização da riqueza deve ser o único objetivo de uma corporação. De acordo com McWilliams e Iegel (2000) muitas empresas têm respondido a essas preocupações, aportando mais recursos em RSC e que outros gestores argumentam que $\mathrm{o}$ investimento em RSC é contrário aos esforços para maximização dos lucros. Assim, Wood (1991), destaca que há um dilema sobre pensar o desempenho social das empresas e a interação subjacente entre os princípios de RSC, o processo de resposta social e as políticas e práticas de geração de riquezas.

Se a viabilidade econômica é o princípio geral dos negócios e a sustentabilidade pautada nas práticas de Responsabilidade Social Corporativas é um aspecto considerado importante para manutenção dos negócios no cenário contemporâneo, a gestão empresarial está diante de um dilema. Considerando a necessidade da continuidade das empresas a partir do lucro e do retorno sobre o capital investido, seria ingênuo o pensamento de que as práticas de sustentabilidade poderiam ser desenvolvidas a partir da elevação dos níveis de consciência dos gestores e investidores. Sendo a sustentabilidade considerada um fator determinante da escolha de parcela dos clientes e fonte orientadora para elaboração de leis e normas que envolvem o mundo dos negócios, então podemos considerá-la como fator competitivo.

A partir do pressuposto de que há complementaridade entre os aspectos de sustentabilidade e viabilidade econômica dos negócios, nos propusemos analisar neste trabalho a existência desta relação. Para confirmar este pressuposto desenvolvemos inicialmente uma análise bibliográfica sobre o tema, destacando os trabalhos sobre viabilidade econômica, sustentabilidade e desempenho econômico. Após levantamento bibliográfico realizamos uma análise financeira comparativa entre empresas integrantes do Índice de Sustentabilidade Empresarial (ISE) da Bolsa de Valores de São Paulo (Bovespa) comparando-as com empresas integrantes do Ibovespa (Índice principal da Bovespa), buscando verificar a existência de diferenças significantes de desempenho financeiro entre os dois grupos.

Este artigo está organizado em cinco seções: a primeira consiste desta introdução que 
visa situar o leitor sobre o que propomos; a segunda apresenta a revisão da literatura, dividida em três subseções: viabilidade econômica; sustentabilidade, ética e responsabilidade social corporativa; e, viabilidade econômica e sustentabilidade. Em seguida apresentamos a terceira seção que trata do desenvolvimento conceitual e a proposição central; na quarta seção apresentamos o método, no qual são destacados os procedimentos de coleta e organização dos dados e o modelo de análise utilizado. Uma análise dos dados obtidos é apresentada na quinta seção e concluímos o artigo apresentando as conclusões destacando os resultados obtidos a partir das análises realizadas, nesta seção apresentamos também as contribuições acadêmicas e gerenciais que este trabalho poderá gerar, as limitações reconhecidas e proposições para pesquisas futuras.

\section{REVISÃO DA LITERATURA}

\subsection{VIABILIDADE ECONÔMICA}

As empresas são constituídas a partir de reservas de capital de outras empresas, de poupança e reservas financeiras de pessoas físicas ou de recursos financeiros captados junto a instituições bancárias, agências de fomento ou de financiamento governamental. Para Luzio (2011), independente da fonte de recursos que lhes deram origem todas estas empresas guardam um aspecto comum entre si, o objetivo de gerar retorno para seus instituidores e investidores. $\mathrm{O}$ retorno financeiro, de acordo com Assaf Neto (2003) é obtido a partir de geração de lucros, ou de excedentes financeiros operacionais e se constituem numa condição que a empresa deve atender para satisfazer a exigência de seus proprietários, instituidores e investidores.

A discussão sobre geração de valor, retorno do capital investido e geração de riquezas, além da geração de empregos e pagamento de impostos é o que constituem a viabilidade econômica de uma empresa. De acordo com Copeland, Koller e Murrin (2001), o valor intrínseco da empresa se baseia na capacidade de gerar caixas futuros ou capacidade de gerar ganhos. Esta posição é corroborada por Rogerson (1997) quando destaca que, dentre os aspectos mais importantes do trabalho dos gestores de negócios estão as decisões de investimento que afetam os fluxos de caixa, seja alterando positivo ou negativamente as receitas, seja aumentando ou reduzindo os custos ou ainda alterando a posição patrimonial da empresa a partir de contas do patrimônio líquido.
No processo de desenvolvimento do negócio as empresas e seus administradores financeiros têm diariamente o desafio tomar decisões que atendam a vários objetivos. Dentre questões que desafiam a gestão estão: as decisões de orçamento de capital - projeções de receitas, custos e despesas operacionais do cotidiano (CARNEIRO; MATIAS, 2011). As decisões de investimentos de longo prazo, quais ativos imóveis, móveis, máquinas, equipamentos e intangíveis - devem ser adquiridas e qual será a capacidade de cada um destes para gerar negócios ou contribuir para a eficiência operacional; as decisões de financiamento: a forma, os custos e as fontes dos recursos necessários para financiar os investimentos requeridos; e, as decisões de curto prazo, quais investimentos e políticas de curto prazo a empresa deve adotar. Para Ross, Wasterfield e Jaffe (2009) este conjunto de decisões definem a viabilidade do negócio no curto e no longo prazo.

Para Fama e Kenneth (1993) um elemento presente em todas as decisões que envolvem compromisso de recursos de uma empresa é o risco. Para os autores a idéias de risco e retorno associados a compromissos de recursos ou investimentos está relacionada na possibilidade do não retorno ou da perda do total ou de parte do capital investido. Dentre decisões que diretores, gestores e controladores têm que tomar, algumas se relacionam com o cotidiano ou futuro imediato da empresa, outras estão ligadas aos investimentos, ou seja, a escolha de opções de onde aplicar o capital com a expectativa de tornar a empresa mais rentável no futuro. Neste sentido, Bruni (2008) sublinha que as decisões de investimentos são estratégicas, por considerar que a lógica que as sustenta não é operacional, mas de longo prazo e se destinam a tornar a empresa mais bem-sucedida. Para o autor estas decisões implicam no investimento de tempo e de dinheiro em um projeto cujo resultado é desconhecido e somente ocorrerá no futuro em um ambiente de risco e/ou de incerteza.

Na denominada teoria clássica de decisão, o fator risco é concebido como o reflexo da variação na distribuição de resultados de um negócio. Para March e Shapira (1987), o risco pode ser medido tanto pela não linearidade (variância) do resultado financeiro quanto pela probabilidade de variância de ganhos e perdas associados à outra alternativa. Desta forma, ao analisar um projeto, deve-se medir sua capacidade real de geração de retorno financeiro, cuja técnica mais conhecida e aplicação da métrica de ROI (Return On Investment) como indicador de desempenho (BRUNI, 2008). Marion (2005) apresenta como a definição de Rentabilidade ou ROI, a capacidade de 
um capital em gerar lucro líquido (retorno) em um horizonte de tempo a partir da geração de fluxos de caixa positivos. Para medir os níveis de retorno, as empresas utilizam a TRI (Taxa de Retorno sobre o Investimento) (MARION, 2005, p. 140) e assim constatam o resultado efetivamente obtido.

Considerando que o financiamento de um projeto ou de um negócio pode ser feito em parte com capital próprio, o custo desse capital deve ser avaliado considerando os custos imputados aos riscos inerentes ao investimento e ao custo de oportunidade, costumeiramente denominado de custo econômico (MARTINS, 2009; p. 234). Para medir o custo econômico ou prêmio associado ao capital próprio e o sacrifício de aplicar estes recursos em uma alternativa e não em outra, Ross, Wasterfield e Jaffe (2009) destacam o método CAPM, acrônimo de Capital Asset Pricing Model (Modelo de Precificação de Ativos Financeiros) como mais adequado, pois, este método considera simultaneamente todos os componentes de risco e de retorno.

O alcance de retornos financeiros depende ainda, do equilíbrio obtido no curto prazo, conforme destaca Assaf Neto e Silva (2012), quando definem que o equilíbrio financeiro de uma empresa é verificado quando suas obrigações financeiras se encontram lastreadas em ativos com prazos de solvência similares aos passivos. Para Méndez, Pérez e Cornejo (2009) a sobrevivência e a liquidez da empresa, depende da sua capacidade de gestão do capital circulante, em síntese, da capacidade de gerar caixa (receitas líquidas) para honrar seus compromissos de curto prazo. O gerenciamento destas contas, sejam as de curto ou de longo prazo, demandam estruturação, ordenamento e controle, exercidos permanentemente pela administração financeira.

As finanças corporativas consistem em uma estrutura de conceitos que ajudam a organizar o pensamento dos diretores e/ou administradores financeiros para maximizar o valor da riqueza dos proprietários da empresa. (SALAZAR, 2010 p. 181).

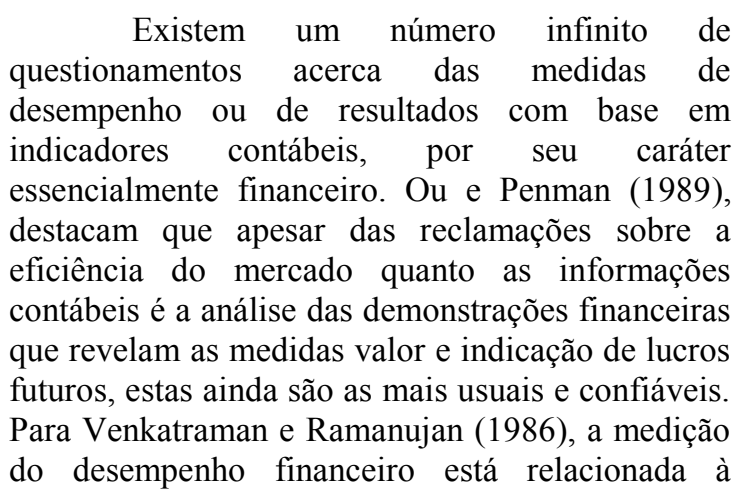

medição da efetividade da empresa, ou seja, da capacidade real de geração de lucro, de retorno e de valor. Desta forma, a viabilidade econômica de uma empresa demanda dedicação, conhecimento e empenho dos gestores no planejamento, gerenciamento e controles dos diversos aspectos relacionados aos indicadores de resultados financeiros.

\subsection{SUSTENTABILIDADE E RESPONSABILIDADE SOCIAL CORPORATIVA}

O desenvolvimento econômico pautado no modelo de expansão industrial, representou até a primeira metade do Século XX um processo de ganhos, de evolução e de progresso. Os meios de produção e a administração dos negócios receberam contribuições das diversas áreas do conhecimento e alcançou altos níveis de eficiência. Para Vergara e Branco (2001), esse inquestionável poder econômico, no entanto, foi obtido com a geração de um custo social inaceitável. Para os autores as múltiplas externalidades negativas associadas à atividade empresarial, sob a forma de degradação da natureza, produção excessiva de resíduos, condições de trabalho impróprias e a produção e distribuição de produtos inadequados às necessidades humanas são aspectos negativos e indesejados pela sociedade.

Considerando que a concepção geral de produtos e serviços se baseia na promessa de gerar conforto, segurança ou prazer, é perceptível que esta promessa não está sendo cumprida. Para Bursztyn (2001 p.10) "há uma frustração da sociedade mundial frente a uma constrangedora pauta de pendências sociais e ambientais a serem encaradas". Para o autor o crescimento econômico das últimas décadas não foi consequente na promoção do desenvolvimento, ou de criação de condições sociais e econômicas capazes de gerar bem-estar em sua completude. Para Aktouf (2004), baseado no pensamento do economista canadense Richard Langlois, o "economicismo" que caracteriza a sociedade contemporânea, que orienta grande parte das ações humanas e subordina sua existência a uma lógica contábil, seria considerado um mal menor, um preço a pagar se esta fosse capaz de aliviasse a miséria e as desigualdades sociais.

Este cenário indica um afastamento das empresas do cumprimento de promessas básicas ou de princípios éticos. Se a ética é uma ciência prática, de caráter filosófico, que norteia os atos do homem na sociedade e orienta à conduta moral nas relações pessoais, comerciais, ou qualquer outra (FRAZÃO; COSTA; NEVES, 2007), quando esta conduta não é moral significa que a ética está sendo 
desconsiderada. Para Patrus-Pena e Castro (2010) existem duas definições de ética: a teoria deontológica na qual a conduta é orientada pelo "dever", independente de suas consequências, e teoria teológica ou consequencial, na qual o critério ético está nos resultados da ação. Para os autores a empresa ética é aquela que adota os pressupostos da sustentabilidade, com respeito, honestidade e olhar fixo no cumprimento de seu papel social, para além do econômico, esta, segundo os autores estaria agindo segundo os preceitos da teoria teológica.

A tecnologia e o conhecimento em gestão acumulados até o presente, no entanto, parecem não ser suficientes para produzir bem-estar e desenvolvimento, há um recorrente questionamento sobre a eficiência e a contribuição efetiva do conhecimento gerado e demanda das empresas uma postura socialmente responsável. Karkotli e Aragão (2010), sublinham que a sociedade atual exige que as empresas na condução de seus negócios possam suprir os bens de consumo e serviços requeridos, pois, ainda há um grande volume excluído do consumo básico; assegurem que no processo de produção e de consumo não sejam gerados efeitos negativos para geração atual e; assegurem ainda que esta produção e consumo não gerem efeitos negativos residuais para as gerações futuras. É a partir desta discussão que Norman e MacDonald (2003) ainda que apresentem uma crítica ao Triple Bottom Line destacam que a proposta deste é relevante neste contexto, a partir da ótica de que o modelo defende que o sucesso das empresas deve ser avaliado para além dos resultados e medidas de caráter financeiro, que neste processo deve-se incluir a ética, a responsabilidade socioambiental para o alcance de desenvolvimento com equilíbrio.

A adoção de políticas de sustentabilidade e de responsabilidade social, no entanto, requer a construção de uma cultura sistemática em todos os setores da organização. De acordo com Ashley et. al. (2005), esta postura deve transcender a filantropia ou o marketing social, as organizações terão que aprender a equacionar a necessidade imperativa de obtenção de lucros para a continuidade do negócio, com obediência às leis que regem os negócios em geral e cada segmento especificamente, além da adoção de um comportamento ético. Equacionar estes aspectos, no entanto, de acordo com Mcguire, Sundgren e Schneeweis (1988) não é uma tarefa fácil. Para os autores há uma visão por parte de grupos de stackholders da existência de uma relação negativa entre responsabilidade social e desempenho financeiro, que os investimentos requeridos para implementação da responsabilidade social geram aumento de custos e, consequentemente deixa a empresa em desvantagem competitiva.
Esta discussão entre a relação negativa entre desempenho social e financeiro, de acordo com Simpson e Kohers (2002), pauta-se nos pressupostos da economia neoclássica, quando defende que os investimentos sociais e ambientais resultam em aumento de custos e redução do lucro e da riqueza para os acionistas. A adoção de aspectos relacionados à sustentabilidade de acordo com Deegan e Rankin (1997) não representa exatamente uma opção para as empresas. Os autores destacam que a sociedade não espera somente lucros das empresas, espera que estas, no desenvolvimento de suas atividades invistam na preservação e no reparo dos inevitáveis danos gerados ao meio ambiente, garantam condições de saúde e de salubridade aos empregados e disponibilizem produtos seguros e adequados aos consumidores.

A centralidade da adoção da sustentabilidade e da responsabilidade socioambiental nos negócios, de acordo com Mattila (2009) é o entendimento dos reais benefícios que a empresa pode obter em termo de competitividade. A imagem corporativa elevada pelo reconhecimento do público consumidor contribui positivamente não somente com a elevação do valor da marca e das ações, mas promove a elevação das receitas a partir da preferência do consumidor e aumento das vendas. Deegan, Rankin e Tobin (2002), destacam, que é a legitimidade e o ganho real, a partir do aumento da riqueza que pode ser a motivação para que as empresas adotem práticas sustentáveis. De acordo com Wood (1991) o denominado desempenho social das empresas a partir da integração entre responsabilidade social, a resposta a sociedade e as políticas desenvolvidas representarão ganhos de imagem, de competitividade e consequentemente de riquezas.

\subsection{VIABILIDADE ECONÔMICA E SUSTENTABILIDADE}

Para analisar a viabilidade econômica os modelos clássicos utilizam-se de fluxos de caixa descontados e o relacionam com o custo do capital pela lógica de risco e retorno. Para Fama e Kenneth (1993) existem uma série de variáveis ad hoc que explicam o retorno através do que os autores denominam de equidade do mercado. Mcguire, Sundgren e Schneeweis (1988), corroboram esta posição e destacam que estudos apontam a existência de atenção às medidas de desempenho baseadas em estudos de responsabilidade social corporativa e que esta é capaz de influenciar o desempenho da empresa. Para Maignan e Ralston (2002) existem três motivações para a prática da 
responsabilidade social: ser um aspecto que auxilia o alcance dos objetivos de rentabilidade, retorno sobre o investimento e aumento de vendas; a obrigação de adotá-la pelas pressões sociais e de mercado para estar em conformidade com as normas de comportamento adequado; e o desejo ou compromisso de gerar impacto positivo, independentemente das pressões sociais.

A relação entre retorno ou desempenho financeiro e responsabilidade social, no entanto, é controversa. Para McWilliams e Iegel (2002) existe uma ausência de relação entre o desempenho social e financeiro e esta se fundamenta basicamente na teoria da oferta e demanda e que os investimentos são realizados na medida em que as empresas percebem que a sociedade e o público consumidor os demandam, porém buscam a manutenção equilíbrio entre esta e a maximização do lucro e de riqueza. De acordo com Simpson e Kohers (2002), há uma relação positiva entre o desempenho social e financeiro, os autores destacam a existência de conflitos entre os custos explícitos (custos de produção, juros, despesas operacionais) e os custos implícitos (perda de receita com baixa qualidade de produto e perda de clientes). Para o autor ao tentar reduzir custos explícitos através de forma irresponsável à empresa acaba por aumentar os custos implícitos e perder competitividade.

Considerando que, a inexistência de viabilidade econômica resulta na descontinuidade da empresa, Garriga e Melé (2004), sublinham que exigências sociais que resultam apenas na imposição de custos devem ser rejeitadas pelos gestores e investidores. Para os autores qualquer ação empresarial e, dentre elas as relacionadas à sustentabilidade somente devem ser aceitas e implementadas se estas forem capazes de gerar uma contribuição efetiva para maximização do valor para o acionista. Qualquer investimento em demandas sociais que produzem um aumento de valor para os acionistas deve ser feito, agindo sem engano e fraude (GARRIGA; MELÉ (2004).

Para Cavalcante, Bruni e Costa (2009) os argumentos de que ações de responsabilidade social e ambiental resultam em custos adicionais e na redução da remuneração dos acionistas, baseia-se na teoria dos shareholders, fundamentada no pensamento de Milton Friedman. Para os autores é necessário que consideremos o que defende a teoria dos stakeholders, que considera os interesses de grupos de interesses de forma mais ampla e desta forma a adoção de práticas de responsabilidade deve ser capaz de contribuir com o alcance de melhor desempenho do negócio. Esta posição é corroborada por Rezende; Nunes e Portela (2008), quando destacam que adesão das empresas a sustentabilidade e a responsabilidade social nos últimos anos tem representado mais que um compromisso ambiental e social, considerando que tem se tornado uma prática o mercado financeiro utilizar informações sociais para classificar e qualificar empresas pelo critério de transparência estabelecido nas leis de governança corporativa.

De acordo com Machado et al. (2012) os motivos pelos quais as empresas aderem ao movimento pelo social, nem sempre são assumidos publicamente. Para os autores, a criação de medidas para avaliar retorno e valorização das ações de empresas social e ambientalmente responsáveis é necessária e estas medidas vêm sendo desenvolvidas de forma a evidenciar que estas empresas estão mais preparadas para o enfrentamento dos riscos econômicos, sociais e ambientais. Um exemplo dos indicadores desta natureza, de acordo com Nunes et al. (2010) é a criação de índices como o Dow Jones Sustainability Index (Índice Dow Jones de Sustentabilidade) da Bolsa de Valores de Nova York, criado em 1999 e o Índice de Sustentabilidade Empresarial (ISE) da Bolsa de Valores de São Paulo, criado em 2005 seguindo uma tendência internacional. Estes índices têm como objetivo premiar empresas que aliam resultados financeiros, eco eficiência, responsabilidade social e transparência nos moldes da "governança corporativa" e da sustentabilidade.

\section{DESENVOLVIMENTO CONTEXTUAL E PROPOSIÇÃO}

Alguns estudos foram desenvolvidos no Brasil com objetivo de analisar a relação entre retorno financeiro da sustentabilidade, a exemplo dos estudos desenvolvidos por Machado, Machado e Corrar (2009), Rezende, Nunes e Portela, (2008) e Cavalcante, Bruni e Costa, (2009). Estes estudos pautaram-se na análise comparativa do desempenho Índice de Sustentabilidade Empresarial da Bovespa (ISE) com os principais índices da bolsa, principalmente os denominados índices amplos (IBovespa, Índice Brasil 50 - IBrX 50, Índice Brasil 100 - IBrX 100 e o Índice Brasil Amplo - IBrA) e concluíram não haver evidências de quaisquer superioridades do ISE em relação aos demais índices que possibilitasse afirmar que a sustentabilidade possui relação positiva com o retorno financeiro.

Desenvolver estudos comparando os índices entre si, no entanto, não representa um método eficiente para $o$ alcance de quaisquer diferenças entre as empresas que os compõem, em função das características destes índices. Analisando o ISE juntamente com os seguintes índices: IBovespa, IBrX 50 e IBrA, constatamos que das 70 empresas que compõem o I-Bovespa 37 
$(52,86 \%)$ compõem o ISE, que das 50 empresas que compõem IBrX 50, 50 (100\%) compõem o IBovespa e que das 51 empresas que compõem o ISE, somente $13(25,49 \%)$ não compõem o IBovespa, 10 (19,61\%) não compõem o IBrX 50 e apenas $7(13,73 \%)$ não compõem o IBrA. Diante destes dados, consideramos que qualquer análise comparativa entre estes índices levará a resultados semelhantes e pouco conclusivos, pois, a maioria das empresas compõem simultaneamente todos eles e desta forma estaríamos analisando ou comparando, basicamente os mesmos dados ou dados com características muito próximas e correlatas entre si, o que não possibilitaria $o$ alcance de grau significante de diferenciação.

Sem discordar das conclusões apresentadas nos estudos anteriores, porém discordando do método utilizado, propomos neste estudo a aplicação de outro método de análise no qual empresas, distintas entre si, possam ser analisadas sem a sobreposição dos dados. Esta análise parte do pressuposto de que a sustentabilidade representa um fator de aumento de resultado financeiro e de viabilidade econômica. A relação entre viabilidade econômica e sustentabilidade que propomos é a de análise dos índices de desempenho econômico (índices de rentabilidade) entre empresas que compõem o ISE e não compõem o IBovespa versus empresas que compõem o IBovespa e não compõem o ISE, desta forma a comparação dar-se-á entre empresas eficientes e sustentáveis versus empresas eficientes e não sustentáveis ${ }^{1}$.

De acordo Assaf Neto (2008), os índices de rentabilidade medem a capacidade econômica da empresa evidenciando o nível de êxito econômico alcançado por ela a partir do capital nela investido. Estes indicadores, baseados em resultados obtidos a partir do ativo total, do patrimônio líquido e das receitas, visam avaliar o desempenho em relação a um determinado conjunto de parâmetros. Desta forma este trabalho foi desenvolvido a partir da seguinte proposição:

1 Esta classificação é meramente para fins de identificação, pois, não dispomos de elementos suficientes para afirmar neste estudo, que as empresas classificadas como "não sustentáveis" não são de fato sustentáveis, tal classificação devese apenas ao fato destas não comporem o ISE, ou seja, não atenderem aos requisitos qualificadores do referido índice.
Há uma relação positiva entre sustentabilidade e viabilidade econômica, quando analisados os índices de rentabilidade entre empresas sustentáveis e não sustentáveis.

\section{MÉTODO}

O método utilizado neste estudo pode ser considerado tal como Gil (2010) define método comparativo, pois, apresenta a intenção de investigar os fenômenos ou fatos objetivando ressaltar diferenças ou similaridades existentes entre eles. Neste estudo o objetivo foi analisar o desempenho econômico de empresas classificadas como sustentáveis e não sustentáveis visando estabelecer a existência de complementaridade ou antagonismo entre viabilidade econômica e sustentabilidade.

\subsection{COLETA DOS DADOS}

Para investigar a proposição deste estudo, a coleta dos dados foi realizada em três etapas, a primeira, o levantamento de dados bibliográficos em livros e artigos publicados em periódicos nacionais e internacionais sobre o tema e as áreas que o fundamentam. A segunda etapa foi realizada a partir do levantamento e análise primária dos dados dos índices no portal da Bovespa na internet (www.bmfbovespa.com.br). A terceira etapa constituiu-se na seleção das empresas a serem analisadas e do levantamento das demonstrações contábeis para realização da análise dos índices de desempenho.

As empresas foram selecionadas de forma aleatória, dentre aquelas que atenderam a classificação estabelecida, mantendo-se o atendimento de um critério base, o de serem empresas de diferentes segmentos de marcado. Após seleção, foram analisados os seguintes indicadores de empenho: a Margem Líquida (indicador de resultado líquido das operações da companhia com base nas vendas brutas) e o Índice de Retorno sobre o Capital.

Próprio Returno on Equity (ROE) (indicador de resultado sobre o capital próprio investido) conforme apresentado nas Tabelas 1, 2, 3 e 4 .

O período selecionado para a realização da análise foi o período compreendido entre os anos 2009 e 2013, escolhido por oferecer as seguintes condições: maturidade do conceito de sustentabilidade, pois, o índice (o ISE) foi instituído em 2005; e, por representar um período pós-crise econômica mundial (crise de 2008) o que 
significa um período de desafios de gestão para obtenção de resultados financeiros. foram:

As empresas sustentáveis selecionadas

- Companhia Energética de Minas Gerais S.A. - CEMIG: empresa concessionária de energia elétrica, controlada pelo governo de Minas Gerais, com ações negociadas nas Bolsas de
Valores de São Paulo, Nova York e Madri (Portal CEMIG, 2014).

- Telefônica Brasil S.A.: empresa de telefonia detentora das marcas comerciais: Vivo para o Brasil, Movistar, para Espanha e países da América Latina; e O2, para Reino Unido, Alemanha, República Tcheca e Eslováquia (Portal Telefônica, 2014).

Tabela 1: Dados da CEMIG S.A.

\begin{tabular}{|l|r|r|r|r|r|}
\hline CEMIG S. $\boldsymbol{A}$. & \multicolumn{5}{|c|}{ Exercício Fiscal } \\
\hline Indicador & $\mathbf{2 0 0 9}$ & $\mathbf{2 0 1 0}$ & $\mathbf{2 0 1 1}$ & $\mathbf{2 0 1 2}$ & $\mathbf{2 0 1 3}$ \\
\hline Receita Operacional Líquida & 12.158 & 12.863 & 15.749 & 14.137 & 14.627 \\
\hline Lucro Líquido & 2.026 & 2.258 & 2.415 & 2.700 & 3.104 \\
\hline Margem Líquida & $16,66 \%$ & $17,55 \%$ & $15,33 \%$ & $19,10 \%$ & $21,22 \%$ \\
\hline Variação Anual & & $5,34 \%$ & $-12,65 \%$ & $24,55 \%$ & $11,11 \%$ \\
\hline Patrimônio Líquido & 11.166 & 11.476 & 11.745 & 12.044 & 12.638 \\
\hline ROE & 0,18 & 0,20 & 0,21 & 0,22 & 0,25 \\
\hline Variação Anual & & $8,44 \%$ & $4,50 \%$ & $9,03 \%$ & $9,56 \%$ \\
\hline
\end{tabular}

Fonte: Elaborado com base nos dados das demonstrações da Cemig S.A.

Tabela 2: Dados da Telefônica Brasil S.A.

\begin{tabular}{|l|r|r|r|r|r|}
\hline Telefônica Brasil S. A. & \multicolumn{5}{|c|}{ Exercício Fiscal } \\
\hline Indicador & $\mathbf{2 0 0 9}$ & $\mathbf{2 0 1 0}$ & $\mathbf{2 0 1 1}$ & $\mathbf{2 0 1 2}$ & $\mathbf{2 0 1 3}$ \\
\hline Receita Operacional Líquida & 14.364 & 14.624 & 14.869 & 12.884 & 51.966 \\
\hline Lucro Líquido & 2.204 & 2.399 & 4.355 & 4.454 & 3.716 \\
\hline Margem Líquida & $15,34 \%$ & $16,40 \%$ & $29,29 \%$ & $34,57 \%$ & $7,15 \%$ \\
\hline Variação Anual & & $6,90 \%$ & $78,56 \%$ & $18,02 \%$ & $-79,31 \%$ \\
\hline Patrimônio Líquido & 11.300 & 11.667 & 43.326 & 44.681 & 43.331 \\
\hline ROE & 0,20 & 0,21 & 0,10 & 0,10 & 0,09 \\
\hline Variação Anual & & $5,41 \%$ & $-51,11 \%$ & $-0,85 \%$ & $-13,96 \%$ \\
\hline
\end{tabular}

Fonte: Elaborado com base nos dados das demonstrações da Telefônica Brasil S.A.

As empresas não sustentáveis selecionadas foram:

- Usina Siderúrgica de Minas Gerais S.

A. - Usiminas: empresa do setor siderúrgico que produz e comercializa aços planos laminados a frio e a quente, bobinas, placas e revestidos, destinados principalmente aos setores de bens de capital e de bens de consumo da linha branca, além da indústria automotiva (Portal Usiminas, 2014).

- VRG Linhas Aéreas S/A: companhia aérea que opera comercialmente com o nome de fantasia GOL Linhas Aéreas, opera voos nacionais e internacionais (Portal da Gol Linhas Aéreas, 2014). 
Tabela 3: Dados Usiminas S.A.

\begin{tabular}{|l|r|r|r|r|r|}
\hline Usiminas S. A. & \multicolumn{5}{|c|}{ Exercício Fiscal } \\
\hline Indicador & $\mathbf{2 0 0 9}$ & $\mathbf{2 0 1 0}$ & $\mathbf{2 0 1 1}$ & $\mathbf{2 0 1 2}$ & $\mathbf{2 0 1 3}$ \\
\hline Receita Operacional Líquida & 10.924 & 11.424 & 10.518 & 12.829 & 12.711 \\
\hline Lucro Líquido & 1.239 & 1.572 & 233 & 17 & -598 \\
\hline Margem Líquida & $11,34 \%$ & $13,76 \%$ & $2,22 \%$ & $0,13 \%$ & $-4,71 \%$ \\
\hline Variação Anual & & $21,35 \%$ & $-83,89 \%$ & $-94,09 \%$ & $-3696,35 \%$ \\
\hline Patrimônio Líquido & 12.150 & 17.433 & 17.284 & 18.513 & 19.014 \\
\hline ROE & 0,10 & 0,09 & 0,01 & 0,00 & - \\
\hline Variação Anual & & $-11,55 \%$ & $-85,04 \%$ & $-93,27 \%$ & $-3569,20 \%$ \\
\hline
\end{tabular}

Fonte: Elaborado com base nos dados das demonstrações da Usiminas S.A.

Tabela 4: Dados da VRG Linhas Aérea S.A.

\begin{tabular}{|l|r|r|r|r|r|}
\hline Gol Linhas Aéreas S. A. & \multicolumn{5}{|c|}{ Exercício Fiscal } \\
\hline Indicador & $\mathbf{2 0 0 9}$ & $\mathbf{2 0 1 0}$ & $\mathbf{2 0 1 1}$ & $\mathbf{2 0 1 2}$ & $\mathbf{2 0 1 3}$ \\
\hline Receita Operacional Líquida & 5.307 & 6.278 & 6.713 & 7.160 & 8.122 \\
\hline Lucro Líquido & 891 & 214 & -752 & -1.513 & -725 \\
\hline Margem Líquida & $16,79 \%$ & $3,41 \%$ & $-11,20 \%$ & $-21,13 \%$ & $-8,92 \%$ \\
\hline Variação Anual & & $-79,67 \%$ & $-428,11 \%$ & $88,74 \%$ & $-57,78 \%$ \\
\hline Patrimônio Líquido & 2.610 & 2.929 & 2.206 & 2.500 & 2.502 \\
\hline ROE & 0,34 & 0,07 & - & 0,34 & - \\
\hline Variação Anual & & $-78,58 \%$ & $-565,92 \%$ & $77,65 \%$ & $-52,14 \%$ \\
\hline
\end{tabular}

Fonte: Elaborado com base nos dados das demonstrações da VRG Linha Aéreas S.A.

\subsection{Análise dos Dados}

Observando os dados apresentados nas tabelas 1, 2, 3 e 4, constatamos os seguintes pontos que, merecem destaque, com relação às empresas sustentáveis, a CEMIG S.A., apresenta margem líquida positiva em todos os exercícios do período analisado com um acumulado de $89,87 \%$ e um ROE médio positivo de $21,07 \%$ no período com tendência de crescimento nos últimos dois períodos. A Telefônica Brasil S.A., apresenta margem líquida positiva em todos os exercícios do período analisado com um acumulado de 102,76\% e um ROE médio de $13,76 \%$ no período com tendência de estabilidade nos últimos dois períodos. Quanto às empresas não sustentáveis, a Usiminas S.A. apresenta uma margem líquida positiva acumulada de $22,74 \%$ no período analisado e um ROE médio de 3,50\%, com tendência acentuada de queda nos últimos dois períodos. A VRG S.A., apresenta uma margem líquida negativa acumulada de $-21,05 \%$ no período analisado e um ROE médio negativo de $-16,42 \%$, com tendência de instabilidade (em baixa) em todos os períodos.

De acordo com os resultados das análises as empresas integrantes do ISE, ainda que não integrantes do IBovespa (empresas sustentáveis) apresentam indicadores de rentabilidade e de retorno melhores que as empresas integrantes do IBovespa e não integrantes do ISE (empresas não sustentáveis). Considerando que o desempenho financeiro no curto/médio prazo resulta na alteração da posição patrimonial e, consequentemente no desempenho das ações das empresas no mercado de capitais, os dados analisados apontam que as empresas sustentáveis apresentam melhor desempenho financeiro. Neste sentido é possível inferir que estas empresas poderão no curto/médio prazo serem incluídas nos índices que focam o desempenho financeiro e ocupar melhores posições no mercado de capitais brasileiro.

\section{CONCLUSÕES}

Neste artigo discutimos a relação entre viabilidade econômica e sustentabilidade na busca da obtenção de elementos ou indícios que apontassem a existência de complementaridade ou antagonismo entre estes dois aspectos. Ainda que considerada um fator decisivo para a criação e a sobrevivência dos negócios no cenário 
contemporâneo de crises sociais, ambientais e econômicas, a sustentabilidade ainda é um aspecto controverso, pois, além da juventude do tema em termos de tratamento deste na gestão dos negócios, há ainda uma visão por parte de muitos gestores sobre uma relação negativa entre esta e a viabilidade econômica. Os defensores da relação negativa destacam o aumento dos custos e o desvio do foco (core business) como as principais causas do desestímulo ao desenvolvimento de políticas e práticas sustentáveis pautadas nos princípios da responsabilidade social corporativa.

Estudos realizados no Brasil analisaram a relação sustentabilidade e retorno com base na análise do ISE, com outros índices de desempenho financeiro e concluíram a não existência de indicações de vantagens do ISE sobre os demais. Questionamos esta comparação neste trabalho argumentando que são praticamente as mesmas empresas que compõem os índices analisados e, portanto, esta composição não permite a obtenção de diferenciações entre eles. Propusemos então uma análise comparativa entre empresas integrantes do ISE e não integrantes do Ibovespa versus empresas integrantes do Ibovespa e não integrantes do ISE com base em indicadores de rentabilidade e de retorno (Margem Líquida e ROE) no período de 2009 a 2013, período pós-crise econômica de 2008.

Os resultados do estudo apontam vantagens consideráveis das empresas integrantes do ISE sobre as empresas não integrantes, tanto em

\section{REFERÊNCIAS}

AKTOUF, O. Pós-globalização, administração e racionalidade econômica: a síndrome do avestruz. São Paulo: Atlas, 2004.

ASSAF NETO, A. Curso de administração

financeira. São Paulo: Atlas, 2008.

ASSAF NETO, A. Finanças corporativas e valor. São Paulo: Atlas, 2003.

ASSAF NETO, A.; SILVA, C. A. T.

Administração do capital de giro. São Paulo: Atlas, 2012.

ASHLEY, P. A. (Coord.). Ética e responsabilidade social nos negócios. 2 . ed. São Paulo: Saraiva, 2005.

BRUNI, A. L. Avaliação de investimentos. São Paulo: Atlas, 2008. termos de desempenho por período quanto o acumulado nos exercícios analisados. Estes resultados, embora não possam ser generalizados em função das seguintes fragilidades do estudo: tamanho da amostra, composta por apenas quatro empresas; heterogeneidade da amostra, são empresas de setores diversos; e dimensão da análise, restrita as análises de rentabilidade e de retorno, apresenta indícios da existência de complementaridade entre sustentabilidade e viabilidade econômica. Ainda que os indícios de relação positiva não sejam tão fortes e inquestionáveis, se consideramos o período analisado é possível inferir que as empresas sustentáveis foram capazes de suportar melhor as crises.

Sem a pretensão de esgotar a discussão sobre o tema, acreditamos que este trabalho represente uma contribuição para a academia e para a gestão empresarial no Brasil quando propõe a inclusão de outras métricas e elementos de análise para avaliação dos impactos das políticas de sustentabilidade nas empresas. Pesquisas futuras poderão ampliar esta discussão e ainda tomar outras vias tais como: comparação entre empresas com diferentes níveis de implementação da sustentabilidade com base nos indicadores do Global Reporting Initiative (GRI); comparação entre empresas do mesmo segmento integrantes ou não de índices econômicos ou ainda, análise de retorno financeiros de práticas específicas tais como o desenvolvimento de produtos sustentáveis.

BURSZTYN, M. Ciência, ética e

sustentabilidade: desafios ao novo século. São Paulo: Cortez; Brasília, DF: UNESCO, 2001.

CARNEIRO, M.; MATIAS, A. B. Orçamento empresarial: teoria, prática e novas técnicas. São Paulo: Atlas, 2011.

CAVALCANTE, L. R. M. T.; BRUNI, A. L.; COSTA F. J. M. Sustentabilidade empresarial e valor das ações: uma análise na bolsa de valores de São Paulo. Revista de Gestão Social e Ambiental, v.3, n.1, p. 70-86, 2009.

COPELAND, T.; KOLLER, T.; MURRIN, J. Valuation: measuring and managing the value of companies. McKinsey \& Company Inc., 2001.

DEEGAN, C.; RANKIN, M. The materiality of environmental information to users of annual reports. Accounting, Auditing \& Accountability Journal, v. 10, n. 4, p. 562-583, 1997. 
DEEGAN, C.; RANKIN, M.; TOBIN, J. An examination of the corporate social and environmental disclosures of BHP from 19831997: A test of legitimacy theory. Accounting Auditing e Accountability Journal, Bradford, v. 15, n. 3, p. 312-343, 2002.

FAMA, E. F.; KENNETH, R. F. Common risk factors in the returns on stocks and bonds. Journal of financial economics, v. 33, n. 1, p. 3-56, 1993.

FLAMMER, C. Does corporate social responsibility lead to superior financial performance? A Regression Discontinuity Approach. Management Science. p. 1-43, 2013.

FRAZÃO, M. F. A.; COSTA, S. S.; NEVES, F. N. O. A dimensão ética da responsabilidade social nas organizações. Maiêutica Digital Revista de Filosofia e Ciências Fins, v. 1, n. 2/3, p. 196-210, 2007.

GARRIGA, E.; MELÉ, D. Corporate social responsibility theories: mapping the territory. Journal of Business Ethics, v. 53, n. 1/2, p. 51-71, 2004.

GIL, A. C. Métodos e técnicas de pesquisa social. 6. ed. São Paulo: Atlas, 2010.

KARKOTLI, G.; ARAGÃO, S. D.

Responsabilidade social: uma contribuição a gestão transformadora das organizações. 4 ed. Petrópolis: Vozes, 2010.

LUZIO, E. Finanças corporativas: teoria e prática, estudos de casos sobre geração e distribuição de valor em empresas. São Paulo: Cengage Learning, 2011.

MARION, J. C. Análise das demonstrações contábeis: contabilidade empresarial. 3. ed. São Paulo: Atlas, 2005.

MÉNDEZ, J. A. P.; PÉREZ, O. C.; CORNEJO, B. G. Gestión del capital circulante y rentabilidade en pymes. En: gestíon del circulante: bases conceptuales y aplicaciones prácticas. Barcelona: Profit Editorial, 2009.

OU, J. A.; PENMAN, S. H. Financial statement analysis and the prediction of stock returns. Journal of Accounting and Economics, v. 11, p. 295-329, 1989.

MAIGNAN, I.; RALSTON, D. A. Corporate social responsibility in Europe and the U.S.: Insights from businesses' self-presentations. Journal of
International Business, v. 33, n. 3, p. 497-515, 2002.

MARTINS, E. Contabilidade de custos. 9. ed. São Paulo: Atlas, 2009.

McGUIRE, J. B.; SUNDGREN, A.

SCHNEEWEIS, T. Corporate social responsibility and firm financial performance. The Academy of Management Journal, v. 31, n. 4, p. 854-872, 1988.

McWILLIAMS, A.; IEGEL, D. Corporate social responsibility: a theory of the firm perspective. Academy of Management Review, v. 26, 2001.

McWILLIAMS, A.; IEGEL, D. Corporate social responsibility and financial performance: correlation or misspecification? Strategic Management Journal, v. 21, p. 603-609, 2000. MACHADO, M. A. V.; MACEDO, M. A. S.; MACHADO, M. R.; SIQUEIRA, J. R. M. Análise da relação entre investimentos socioambientais e a inclusão de empresas no índice de sustentabilidade empresarial (ISE) da BM\&FBovespa. Revista de Ciência da Administração, v.14, n. 32, p. 141156, 2012.

MACHADO, M. R.; MACHADO, M. A. V.; CORRAR, L. J. Desempenho do índice de sustentabilidade empresarial (ISE) da bolsa e valores de São Paulo. Revista Universo Contábil, v. 5, n. 2, p. 24-38, 2009.

MATTILA, M. Corporate social responsibility and image in organizations: for the insiders or the outsiders? Social Responsibility Journal, v. 5, n. 4, p. 540-549, 2009.

MARCH, J. G.; SHAPIRA, Z. Managerial perspectives on risk and risk taking. Management Science, v. 33, n. 11, p. 1404-1418, 1987.

NORMAN, W.; MACDONALD, C. Getting to the bottom of "Triple Bottom Line". Business Ethics Quarterly, v. 14, n. 2, p. 243-262, 2003.

NUNES, J. G.; TEIXEIRA, A. J. C.; NOSSA, V.; GALDI, F. C. Análise das variáveis que influenciam a adesão das empresas ao índice BM\&F Bovespa de sustentabilidade empresarial. Revista de Administração e Contabilidade da Unisinos, v. 7, n. 4, p. 328-340, 2010.

PATRUS-PENA, R.; CASTRO, P. P. Ética nos negócios: condições desafios e riscos. São Paulo: Atlas, 2010. 
REZENDE, I. A. C.; NUNES, J. G.; PORTELA, S.

$\mathrm{S}$. Um estudo sobre o desempenho financeiro do Índice Bovespa de Sustentabilidade Empresarial. Revista de Educação e Pesquisa em

Contabilidade. v. 2, n. 1, p. 71-93, 2008.

ROGERSON, W. P. Intertemporal cost allocation and managerial investment incentives: a theory explaining the use of economic value added as a performance measure. Journal of Political Economy, v. 105, n. 4, p. 770-795, 1997.

ROSS, S. A; WESTERFIELD, R. W.; JAFFE, J. F. Administração financeira. 2. ed. São Paulo: Atlas 2009.

SALAZAR, G. T. Fundamentos de finanças corporativas: teoria e aplicações práticas. São Paulo: Atlas, 2010.

SIMPSON, W. G.; KOHERS, T. The link between corporate social and financial performance: evidence from the banking industry. Journal of Business Ethics, v. 35, n. 2, 2002.

TSOUTSOURA, M. Corporate social responsibility and financial performance. Berkeley: Applied Financial Project, 2004.

WOOD, D. J. Corporate social performance revisited. Academy of Management Review. v. 16, n. 4, p. 691-718, 1991.

VENKATRAMAN, N.; RAMANUJAN, V. Measuring of business performance in strategy research: a comparison of approaches. Academy of Management Review, v. 11, n. 4. P. 801-814, 1986.

VERGARA, S. C.; BRANCO, P. D. Empresa humanizada: a organização necessária e possível. Revista de Administração de Empresas, v. 41, n. 2, p. 20-30, 2001. 